\title{
Seeing all beings as oneself: internationalizing higher education for universal harmony
}

\section{Kalyani Unkule}

Jindal Global University

\begin{abstract}
:
The tenets of Hinduism share a complicated relationship with international higher education for an important reason: the purported taboo over crossing oceans. The ethos of Hinduism, however, is deeply embedded in a posited harmony of individuals and cultures. This makes it a faith that at once embraces the value of intercultural exchange while challenging contemporary understandings of how it is best achieved. Rabindranath Tagore espouses this philosophy summing it as he alone sees, who sees all beings as himself. Implications for internationalism in higher education will be teased out from the spiritual and religio-cultural underpinnings of Tagore's experiments in the field, namely, Vishwa Bharati and Shantiniketan help clarify the Hindu basis for internationalism. The paper will then argue that the deeply entrenched Western-centric bias in what is increasingly described as "global" higher education defeats the true motivations of internationalization of the University. It will further explore the ways in which reference to religion (Hinduism in particular), not just in structuring curriculum for foreign students, but in reimagining the basis for globalization of higher education could potentially counter these trends towards homogenization and reset internationalization efforts on a more meaningful trajectory.
\end{abstract}

\section{Introduction}

The tenets of Hinduism share a complicated relationship with international higher education for an important reason: the purported taboo over crossing oceans. This taboo was strictly applied in case of the Brahmins, who also happened to be the caste with near-monopoly over access to and imparting of education. The ethos of Hinduism, however, is deeply embedded in a posited harmony of individuals and cultures. A spiritual text identified with Hinduism, the Chandogya Upanishad, for instance, contains dedicated segments exploring such themes as tattvamasi or the connection of one's innermost self to the divine soul and the doctrine of bbuma or infinity. This makes it a faith that at once embraces the value of intercultural exchange while challenging contemporary understandings of how it is best achieved. Rabindranath Tagore espouses this philosophy summing it as he alone sees, who sees all beings as himself. Implications for internationalism in higher education will be teased out from the spiritual and religio-cultural underpinnings of Tagore's experiments in the field, namely, Vishwa Bharati and Shanti Niketan. The paper will then argue that the deeply entrenched Western-centric bias in what is increasingly described as "global" higher education defeats the true motivations of internationalization of the University. It will further explore the ways in which reference to religion (Hinduism in particular), not just in structuring curriculum for foreign students, but in reimagining the basis for globalization of higher education could potentially counter these trends towards homogenization and reset internationalization efforts on a more meaningful 
trajectory. Spiritual learning, rather than multiculturalism, will be proposed as the better approach to conceptualizing internationalization of the University. This approach holds particular promise for emerging countries who have thus far been unable to fulfil their potential to offer meaningful learning experiences for foreign students due to their higher education institutions being unfavourably compared with Western counterparts.

This paper will explore the inherent internationalism and its ramifications for seeking and receiving education abroad of a certain religious tradition. The religious tradition in question is Hinduism. Following the introduction, some key founding ideals of Hinduism are listed and set in context. The meaning of education and higher learning are then characterized based on the principles outlined. The following section reviews current trends in study abroad and calls for a fundamental change in the dominant paradigm, proposing instead, an alternative paradigm based on principles of Hinduism. In conclusion, the implications of this alternative model for individuals and institutions are considered.

\section{Important Principles of Hinduism}

Hinduism is essentially a way of life. It has been systematized as a religion, primarily with reference to vocabulary belonging to other belief systems. There are, none-the-less, a broadly recognized set of tenets that constitute the core of the Hindu world-view.

Belief in a supreme, divine reality is the point of departure of Hindu philosophy. However, the nature of such reality is not to be rigidly defined. Instead, according to Hindu scripture, truth is one, but the wise describe it in many ways. There is recognition of the transient and ever-changing nature of all that exists. According to Devdutt Pattanaik, "time (kala) plays a key role in Hindu mythology. Buddhism, Jainism and Hinduism speak of a world that has no beginning (anadi), no end (ananta) and is always impermanent (anitya)" (Pattanaik, par. 5) Thus, Hinduism makes way for oneness and inclusivity while acknowledging the observed facts of diversity and impermanence.

The Upanishads reflect this quest for balance. "The Upanishads are a collection of Hindu sacred texts that were recorded in Sanskrit over the course of some two thousand years, through the end of the Middle Ages. The majority were composed between 500 BCE and 200 BCE but likely began earlier in an oral tradition. They are meant to be read in the form of instruction, teaching, or dialogue between guru and student. (...) At the heart of the Upanishads is a process for investigating ultimate truth, such that one might understand the nature of reality and the soul might become freed from the physical body" (Fahey, p. 197).

The Chandogya Upanishad contains dedicated segments exploring such themes as tattvamasi or the connection of one's innermost self to the divine soul and the doctrine of bhuma or infinity. The soul is inseparable from the divine spirit. The essence of this Upanishad is identification of the self with the Universe. Such identification is key to mastering oneself and finding infinite joy and freedom.

Abimsa or non-violence is an essential value in Hinduism. It stems from the hypothesis that God pervades all beings, living and non-living. Thus empathy is a core value in Hinduism that upholds the intrinsic worth of the other, bridges the gap between self and other, and elevates harmonious existence with nature to the very founding ideal of the good life. It further encourages 
the practice of seeing all beings as oneself, which is a central theme for the argument made later in this paper.

The Hindu education system is built around what is known as the "guru-shishya parampara". This tradition is premised on the singular bond between the wise master and his disciple. In the priestly, warrior and trading classes, living with and studying under the tutelage of the master-teacher were widely practiced. Learning in Hindu societies is typically associated with memorization and recital of ritual texts across much of academic literature and discourse. However, this is a highly restricted view of the system. In fact, equal emphasis on developing specialized knowledge and skills to suit one's purpose in society and development of a broad base of general understanding is a hallmark of the Hindu approach to education.

Another distinguishing marker of Hinduism is that it de-emphasizes conformity as the basis for membership. Agreement with a certain set of dogmas or rules is not a strict requirement for identification with the faith. This is an important difference from other religions and also why it can be instructive in the context of established models in academia. In the academic world too, membership into a scientific community is rule based. Broadly-speaking, the language and techniques of positivist scientific enquiry must be mastered. Some systems allow more crossdisciplinary conversations than others but, by and large, most research and teaching continues to be practiced within disciplinary silos.

Based on the philosophical contours sketched above, how can one describe the meaning of education from a Hindu perspective? It may be said first and foremost, that the quest for knowledge is inspired by the need to relate the local with the universal, the self with the subliminal and the situational with the transcendental. There is an implicit sense that there is higher meaning but far from being divorced from the immediate and the mundane, that higher meaning is to be explored through them. An element of universality is associated with human preoccupations; yet, the approaches to finding answers are distinctly local.

Shiv Visvanathan's critique of a western-dominated approach to science helps clarify the distinction between a dominant paradigm and alternative models that are rendered peripheral due to the existence of the former. Visvanathan says "alternative sciences have always existed whether one considers Ayurvedic medicine or traditional agriculture. Only these sciences never made a claim to a universalizing validity that modern western science insisted upon. In fact, it is only modern western science that has systematically adhered to its claims to be the universal basis of knowledge" (Visvanathan, p. 1). His words "Knowledge rather than being an abstract entity or system becomes a life world connected to livelihood, lifestyles and life cycles" (Visvanathan, p. 167) well encapsulate the Hindu epistemological approach.

Secondly, since conformity is not insisted upon, there is space for curiosity and argumentation. Lacking a designated holy book, the tenets of Hinduism are dispersed across various texts. Contextual reading and attempts at reinterpretation via argumentation have organically resulted from this fact. 


\section{Current outlook on study abroad}

Internationalization has been a major goal pursued by universities for the past two decades at least. Efforts in this direction are motivated by practical concerns such as earning greater revenues in tuition as well as other objectives like promoting diversity. To an external audience, internationalization has been justified by highlighting its potential to enhance the financial viability and stability of the tertiary education sector. In addition, attractiveness of a country's universities for foreign students has been widely seen as an element of soft power. In The Study Abroad Solution: How to Open the American Mind, Sanford Ungar advocates study abroad as a way of combating the United States' growing disconnect with the rest of the world in the post-Cold War era (Ungar, 2016). There have even been some studies conducted to determine the impact of study abroad on related objectives within the university system such as degree completion (O’Rear et al., 2012).

However, little has been said in the way of study abroad's potential to encourage inter-faith dialogue and assist inter-cultural understanding. The first reason for this is that study abroad has generally been studied under the broader rubric of internationalization rather than as a separate unit. Internationalization is an assemblage of initiatives not restricted to student mobility. According to Craciun, "mastering the literature on internationalization is made difficult by:

1. the proliferation of different labels associated with the historical development of internationalization: "re-internationalization," "postinternationalization," "globalized internationalization"

2. the coexistence of various scales of analysis: "internationalization versus Europeanization" “internationalization versus globalization", "Europeanization versus internationalization versus globalization";

3. the development of similar parallel processes across different scales: "demonopolization", "de-institutionalization", "de-nationalization";

4. the plethora of policy measures that come under the 'banner concept of internationalization', i.e. international student mobility, collaborative research, development of curricula and strategies for teaching and learning, the establishment of institutional networks (Craciun, p. 79).

Craciun's analysis above is instructive for the second reason, namely, standardization or Europeanization of the study abroad experience. The experience that students have when they spend a period of study in Western institutions has been packaged and replicated by counterparts the world over. Competitive pressures to attract foreign students have led institutions to move towards homogenizing the student experience, rather that nurturing diversity of experiences, which should be the true objective of study abroad.

However, discussion of study abroad in the context of globalization inevitably creates a hierarchy of "good practice" with what Western institutions have to offer coming out on top. The rest are then expected to aspire to those standards or lose out in a fiercely competitive environment.

As an administrator of international student mobility programs, I often find myself torn between an expected level of professionalism based on standardized expectations and a more wholesome immersion into local culture, society and professional environments. Striking a balance 
between the two is not merely an ideational exercise. It goes to the heart of the question as to whether non-western education systems are worthy and viable contenders as receiving institutions for international students. Such an institution would need to work out how to make the experience unique enough without being entirely unstructured or overwhelming students with a sense of culture shock. For instance, many exchange or study abroad students might expect an induction or orientation program at an Indian institution, along the same lines as they would have experienced at home universities in another part of the world. A very structured initiation into an Indian university is possible and largely desirable at an institutional level. However, it could potentially set misplaced expectations about how things work in the wider socio-cultural milieu and deprive an individual of the opportunity to experience, successfully navigate and gain from more authentic, well-rounded exposure and, therefore, develop practical skills. This example goes to the heart of the question as to whether study abroad should be viewed as simply an academic experience or a life-experience, where the former is simply an off-shoring of part of the degree requirements of a student while the latter refers to a well-rounded formative experience for the individual.

Immersion in the host culture is the distinguishing marker of study abroad when compared with other kinds of travel experience (Gray \& Savicki, 2015). A study abroad experience rooted in local culture in this way would be an eminent strategy to combat trends towards homogenization under the banner of global education because as Brabazon states simply and tellingly, "Education based in Perth should be different from that offered in New York, Brighton or Osaka" (Berg \& Seeber, p. 51).

Knight's definition of internationalization of higher education as "the process of integrating an international, intercultural or global dimension into the purpose, functions or delivery of postsecondary education" most fittingly encapsulates the more comprehensive vision set out here (Knight, p. 11).

\section{The Hindu view on study abroad}

The tenets of Hinduism share a complicated relationship with international higher education for an important reason: the purported taboo over crossing oceans. The Dharmashastras or the texts on the science of righteous conduct proscribe travel. Since these texts are concerned with the ritual aspects of religion, scholars have inferred that travel was not favored since it hampered practice of daily rituals. This taboo was strictly applied in case of the Brahmins, who with time came to be the caste with near-monopoly over access to and imparting of education. Prevailing practice among merchant classes differed slightly, whereby, having crossed the seas, they were required to undergo a purification ritual or face the threat of excommunication. It has been suggested that the intensity of application of this taboo increased with contact with Europeans, until the breakthrough came in the nineteenth century with social reformers from various parts of India openly flouting this prohibition.

Hindu social reformers placed education at the heart of social change. They advocated education for lower classes as vital to diminishing the exploitative excesses of the caste system. They invited scorn and contempt when they espoused the cause of women's education as panacea to abhorrent practices like child marriage and sati. Some defied obligations and restrictions associated 
with their caste status by seeking education or travelling abroad. Almost all couched their progressive views in an indictment of dogmatic and regressive interpretations of Hindu scriptures.

The Hindu view on study abroad would urge not only a rethink of how study abroad programs are conducted but also a radical reimagining of higher education. Just as reaching out for contact with and learning from the rest of the world were made possible only by acts perceived as anathema to the religious code, it is conceivable that new strategies of internationalization might even entail radical departures from established positions in the world of higher education.

Seen from this perspective, higher education ceases to be a cosmetic appendage to getting a university degree. The quest for enhancing ones understanding and appreciation of diversity becomes instead, a central purpose of seeking university-level education.

As discussed above, Hinduism discourages conformity and valorizes the potential of the immediate as a bridge to the universal. This emphasis on the local would inspire universities to reflect on what unique aspects of their context and surroundings should be incorporated in their pedagogy and campus culture. This would make each individual location attractive for the student aspiring for a study abroad. To understand these ideas in operation Rabindranath Tagore's ideas and initiatives in the field of education are instructive.

Rabindranath Tagore was a late nineteenth and early twentieth century public intellectual, educator and innovator in the field of education. He is equally known as a literary figure and was awarded the Nobel Prize in Literature in 1913. The official website of the Nobel Prize describes his writing as profoundly sensitive, fresh and beautiful (Nobelprize.org. Nobel Media AB 2014), but in addition, it is also nuanced, laden with symbolism, compelling and groundbreaking.

Tagore was staunchly critical of the hegemonic homogenization of systems of education referred to above. He was opposed to blind emulation of the European model and emphasized the need to view European universities as products of their individual context. At the same time he argued against complete rejection of the Western experience and lauded institutions there for remaining rooted in local traditions.

Tagore was well aware of the enriching imprint that contact with foreign cultures had left on the Indian civilization and he appreciated the need for local education systems to make their presence felt globally. His writings discourage isolationism and extoll the virtues of cooperation and coordination. He tried to synthesize these ideas by arguing against the extremes of isolation and homogenization.

With universal harmony being the key driving force behind his educational projects, it is unsurprising that Tagore's school was named Shantiniketan or the abode of peace and his university, Vishwa Bharati, has often been described as the place where the world makes its home in a single nest. Through his emphasis on an open curriculum and inner development, Tagore sought at once to challenge the restrictive methods of conventional education and parochialism in one's outlook towards life. 


\section{A methodological framework to assess outcomes of study abroad based in principles of Hinduism}

The existence of diverse models of study abroad need not mean an unquestioning acceptance of uniqueness for its own sake. For justifying the resources and efforts needed to sustain study abroad programs, one should still have the means to assess their impact. In the concluding section, I outline a framework for such assessment, with attention to the outcomes for the individual as a student, lessons for future professional life and growth and lessons for interaction between universities and their social-context.

\section{Intercultural competence}

Wong summarizes the difficulty of measuring intercultural competence developed because of the study abroad experience thus:

Intercultural competence is a complex construct unlikely to be fully captured by a single instrument. The lack of change on a particular measure of intercultural competence may suggest a problem with the measure, rather than the student or program. Furthermore, researchers need to examine their expectations about the magnitude, rate, and consistency of students' intercultural growth. Therefore, when identifying the "problem" with study abroad, we should devote as much attention to critiquing our measures as we devote to critiquing our students and programs. (Wong, p. 133)

Yet, the most commonly held notion of intercultural competence is that of developing a knack for spotting and dealing with difference. Thus, difference, rather than shared attributes, becomes the focus of cross-cultural exploration and the intended learning outcome of cross-cultural immersion becomes a cursory familiarity that is instrumental in nature and not an end in itself. One measure proposed on the basis of Hindu ontology would be feeling a greater proximity to something outside of oneself and the immediately familiar or seeing all beings as oneself which would propound a more radical objective for the study abroad experience. Here, one is able to look beyond difference and develop a profound realization of the common essence of all human nature and even further, of all that exists.

Immersed in a study abroad experience steeped in the principles of Hinduism, a student would begin to experience the pervasive oneness of all life. The student would be encouraged to develop an affinity for all that surrounds her as a figment of the same supreme, divine reality. In the first instance, this signals realization of one's innate sense of empathy. A deepening and further extension of this empathy opens the door for abimsa, or non-violence, another important principle in the Hindu world-view.

\section{Future learning and growth}

Since a study abroad period is typically brief, it would be better understood as a point of departure rather than a complete learning experience whose outcomes are measurable immediately thereafter. Proficiency in intercultural understanding should be in evidence long after, and reflect in the individual's professional and personal dealings. One implication of the "seeing all beings as oneself" approach is this element of evolution with the study abroad experience being the launch pad to a life-long trajectory of perceptiveness and acceptance. Lewis et al. speak of the concept of "mindful wonderment" which they describe as "a way to maintain open wonder and curiosity about 
possibilities for seeing, hearing and even responding to others from a fresh perspective" (Lewis et al., p. 82). This approach also underscores the processual aspect of intercultural understanding as an ongoing phase of expansive curiosity. Applied to the study abroad experience, it translates as the opportunity to develop the temperamental agility for global engagement and exploration. More importantly, however, it incorporates the concept of mindfulness into the equation between study abroad and intercultural competence, explaining that attainment of the latter is predicated on a conscious choice to immerse oneself in the destination's circumstance.

\section{Implications for role of universities in society}

The utility of university education is being called into question by governments, prospective students, employers and society-at-large, and whether it enhances one's chances of leading a successful and fulfilling life is today increasingly contested. The traditionally pervasive correlation between being college educated and getting a well-paying job and being able to afford a family or being a respected member of society, is now blurred in people's minds. There is also more debate over whether universities exist for private benefit or public good and to what extent they have become inward looking institutions focused only on their own interests. According to New America's annual higher education survey, while 42 percent of respondents feel that higher education leaders put students first, 44 percent believe that higher education leaders put the longterm interests of their institutions first (New America; The Expectations Gap, par. 4).

Some even argue that academia itself is no longer the forum for open-minded debate and enquiry, it claims to be. One such critical voice is that of Musa al-Gharbi, a Sociologist at Columbia University who says,

...if one wanted to create an environment that actually promoted closed-mindedness and dogmatism, contemporary research suggests the following prescription: consolidate society's most intelligent, knowledgeable and charismatic people, at a time in their lives when their identities are just taking shape, in a competitive environment focused largely on the sciences. In other words, set up a university (Al-Gharbi, par. 4).

One way to bridge this widening chasm could be to move away from rhetoric that alienates universities from the public through projection of an implicit superiority and, instead, to emphasize the ways in which they are fulfilling an important role relevant to the wider social context.

A redesign of study abroad is certainly not the magic bullet with solutions to all these problems. However, it does carry immense potential for allowing universities to reimagine their raison d'etre and align themselves more closely with the needs and aspirations of the societies they serve. This, in turn, will enhance their legitimacy, making them more powerful agents for change. It will also set higher education systems everywhere on a more equal footing, rather than the current segregation between sending and receiving regions. Universities that are true to their social, religious and cultural contexts will in all probability offer a unique point of view, a different pedagogy and hence a study abroad experience distinguishable from any other. This will make each of these experiences valuable in its own right rather than a current scenario where a single set of parameters is used to judge all, resulting in a hierarchy. Once we make room for such co-existence of alternatives, seekers of an educational experience in development of empathy, well-rounded professional and life skills and 
refined appreciation of the oneness of the local and global may see their chances in a study abroad experience rooted in Hinduism.

\section{Works Cited}

Al-Gharbi, Musa. A lack of ideological diversity is killing social research. https://www.timeshighereducation.com/opinion/lack-of-ideological-diversity-is-killing-socialresearch?utm_source=the_editorial_newsletter\&utm_medium $=$ email\&utm_content=other_stories\&u tm_campaign=the_editorial_newsletter, Web. 17 Nov 2017.

Berg, M. \& Seeber, B. K., The Slow Professor: Changing the Culture of Speed in the Academy, University of Toronto Press 2016.

Brabazon, T., The University of Google: Education in the (Post) Information Age, Ashgate Publishing, Ltd., 2012.

Craciun, D., "Systematizing internationalization policy in higher education: Towards a typology", Internationalisation in Higher Education: Management of Higher Education and Research, Vol. 3, Issue 1, May 2015.

Fahey, D. M. (Ed.) Milestone Documents of World Religions, Upanishads. Salem Press Inc., 2010.

Gray, K. M. \& Savicki, V., "Study Abroad Reentry: Behavior, Affect, and Cultural Distance", Frontiers: The Interdisciplinary Journal of Study Abroad, Vol. 26, Fall 2015, pp. 264-278.

Lewis, R., Davis Lenski, S., Mukhopadhyay, S., \& Cartwright, C. T. (2010). "Mindful wonderment: Using focus groups to frame social justice". Journal for Social Action in Counseling and Psychology. Vol. 2, No.2, 2010, pp. 82-105.

Knight, J., "Internationalization Remodeled: Definition, Approaches, and Rationales", Journal of Studies in International Education, Vol. 8, Issue 1, 2004, pp. 5-31.

New America's Annual Higher Education Survey. "The Expectations Gap", available at https://www.newamerica.org/in-depth/varying-degrees/expectations-gap/.

Nobel Prize in Literature, 1913. http://www.nobelprize.org/nobel prizes/literature/laureates/1913, Web. 17 Nov 2017.

O'Rear, I., Sutton, R. L., \& Rubin, D. L., "The Effect of Study Abroad on College Completion in a State University System," U.S. Department of Education, International Research Studies Office, 2012; https://www.academia.edu/3073570/The_Effect_of_Study_Abroad_on_College_Completion_in_a_S tate_University_System

Pattanaik, Devdutt, "Is One Belt, One Road the Chinese ashwamedha?", Times of India, May 23, 2107.

Ungar, S. J. "The Study Abroad Solution: How to Open the American Mind", Foreign Affairs, Vol. 95, No. 2, March/April 2016, pp. 111-123.

Visvanathan, S., "Alternative Science”, Theory, Culture \& Society, Vol. 23, Issue 2-3, 2006, pp. 164-169.

Wong, E. D., "Beyond 'It was Great'? Not so Fast!", Frontiers: The Interdisciplinary Journal of Study Abroad, Vol. 26, Fall 2015, pp. 121-135. 